\title{
Functional constipation and overactive bladder in women: a population-based study
}

\author{
Glícia Estevam de ABREU, Eneida Regis DOURADO, Danielle de Novais ALVES, Milly Queiroz de ARAUJO, \\ Natália Souza Paes MENDONÇA and Ubirajara BARROSO JUNIOR
}

ABSTRACT - Background - An association between urinary disorders and functional constipation has been registered in children and adults, with functional constipation being a common complaint in individuals with overactive bladder. Objective - To evaluate the prevalence of functional constipation, overactive bladder and its dry/wet subtypes in women and to determine which bowel symptoms predict overactive bladder. Methods - A cross-sectional study of women randomly approached in public spaces. Exclusion criteria: neurological/anatomical abnormalities of the bowel or urinary tract. Constipation was defined as $\geq 2$ positive symptoms of those listed in the Rome criteria. Urinary abnormalities (frequent urination, urgency, incontinence, nocturia) were defined by a score $\geq 2$ in the respective item of the International Consultation on Incontinence Questionnaire - Overactive Bladder. Dry overactive bladder was defined as urgency without incontinence, while wet overactive bladder included incontinence. Results - A total of 516 women with a mean age of $35.8 \pm 6$ years were interviewed. Rates of functional constipation, overactive bladder, dry overactive bladder and wet overactive bladder were $34.1 \%, 15.3 \%, 8.9 \%$ and $6.4 \%$, respectively. Functional constipation was associated with overactive bladder and dry overactive bladder, with functional constipation predicting dry overactive bladder ( $\mathrm{OR}=2.47)$. Quality of life was poorer in constipated women compared to non-constipated and even worse in constipated women with wet overactive bladder (median 22.5; 95\%CI: 17.25-35.25). Manual maneuvers were significantly associated with both overactive bladder subtypes. Independent predictive factors for overactive bladder were manual maneuvers $(\mathrm{OR}=2.21)$ and $<3$ defecations/week $(\mathrm{OR}=2.18)$, with the latter being the only predictive factor for dry overactive bladder $(\mathrm{OR}=3.0)$. Conclusion - Functional constipation is associated with overactive bladder and its dry subtype, particularly in the younger population. In addition, this association is responsible for lower quality of life scores, especially when urinary incontinence is present. The presence of manual maneuvers and less than three defecations per week should direct us to look for overactive bladder.

HEADINGS - Constipation. Overactive urinary bladder. Women. Lower urinary tract symptoms, complications. Adult health.

\section{INTRODUCTION}

Functional constipation $(\mathrm{CF})$ is a frequent complaint at medical appointments and its prevalence in the general population is approximately $16 \%{ }^{(1)}$. In adults, $\mathrm{FC}$ is more common in women, the elderly and low-income individuals, and may have negative repercussions on quality of life due to frequent need for repeated treatments ${ }^{(1)}$. Presently, Roma IV criteria is the most commonly instrument used for clinical diagnosis of this bowel dysfunction ${ }^{(2)}$.

The association between FC and urinary symptoms has been well described in the pediatric population. In a recent study, our research group showed that a constipated child is 6.8 times more likely to develop lower urinary tract dysfunction ${ }^{(3)}$. In adults, an association between urinary disorders and FC has also been registered, with $\mathrm{FC}$ being more common in individuals with overactive bladder $(\mathrm{OAB})$ than in those without $\mathrm{OAB}^{(4)}$. $\mathrm{FC}$ is a predictor of the intensity of $\mathrm{OAB}$ and is associated with moderate to severe urinary symptoms ${ }^{(5)}$.

Several questionnaires have been proposed for the evaluation of OAB. The International Consultation on Incontinence Questionnaire - Overactive Bladder (ICIQ-OAB) has proved to be a useful tool for the diagnosis of $\mathrm{OAB}$, particularly because it is able to measure the impact of this dysfunction on quality of life ${ }^{(6)}$. Nevertheless, to the best of our knowledge, there are no studies in the literature associating the ICIQ-OAB and its quality of life score with the Rome criteria for FC in population-based studies. Furthermore, no description has been made of which bowel symptoms listed in the Rome criteria are more closely associated with this urinary dysfunction and its wet and dry subtypes (OAB with and without urinary incontinence).

The objective of this population-based study was to assess the prevalence of FC, OAB and the dry and wet subtypes of OAB in women. In addition, the study was designed to identify which of the Rome criteria are more closely associated with urinary symptoms in ICIQ-OAB and constitute associated factors for OAB and its subtypes. This evaluation should provide further information on the association between FC and OAB and may be useful in improving management of these dysfunctions.

Declared conflict of interest of all authors: none

Disclosure of funding: no funding received

Centro de Distúrbios Miccionais na Infância, Escola Bahiana de Medicina e Saúde Pública, Salvador, Bahia, Brasil.

Corresponding author: Glícia Abreu. Orcid: 0000-0003-3170-2294. E-mail: gliabreu@hotmail.com 


\section{METHODS}

A cross-sectional study was conducted with women randomly approached in public spaces in a Northeast Brazilian city. Care was taken to choose data collection sites frequented by individuals of different socioeconomic levels between June and August 2017. The research team consisted of a colorectal surgeon, a urologist, a general practitioner, and five medical students. Before starting the survey, all interviewers were trained on issues related to bowel and urological disorders, so they could answer the doubts of the women during application of the self-administered questionnaire. After having signed an informed consent form, all participants answered a self-report questionnaire inquiring about their demographic characteristics (age, schooling and number of childbirth deliveries) and about the presence of constipation and urinary symptoms. All questionnaires answered were immediately reviewed by the research team to avoid data loss. The inclusion criteria were women $\geq 18$ years old and over willingness to sign the informed consent form. Women who reported neurological disease or diagnosed gastrointestinal and urinary tract abnormalities which need regular medical follow-up were excluded from the study population. The research team didn't have any previous contact with the women before the interview and none gastrointestinal or urology recommendations were given to improve those dysfunctions. Women were not remunerated for having answered the questions. The institution's internal review board approved the study protocol.

Constipation was assessed using the validated Rome IV criteria, which consists of six questions about the presence or absence of: Straining during more than $1 / 4$ defecation; irregular or hard stools Form Scale 102) more than $1 / 4$ defecation; Sensation of incomplete evacuation more than $1 / 4$ defecation; sensation of anorectal blockage more than $1 / 4$ defecation; manual maneuvers to facilitate more than $1 / 4$ of defecation (e.g. digital evacuation, pelvic floor support); fewer than three spontaneous defecations/week. Constipated woman was defined as at least two positive symptoms of the following for a period of three months with symptom onset at least 6 months prior to diagnosis.

The International Consultation on Incontinence Questionnaire - Overactive Bladder (ICIQ-OAB) was used to evaluate symptoms of an overactive bladder. This questionnaire had already been validated for use in Portuguese language and consists of four main questions regarding daytime and nighttime urinary frequency and the presence of urgency and incontinence. Women who reported having "sometimes" experienced urgency and incontinence in the previous month (a score of 2) were considered to have these symptoms, while women who reported waking up to urinate at least twice during the night (a score of 2) were defined as having nocturia; and those who urinated more than 9 times/day (a score of 2) were defined as having frequent daytime urination. $\mathrm{OAB}$ was defined as the presence of urgency in the four preceding weeks. The presence of OAB without urinary incontinence was defined as dry $\mathrm{OAB}$, while the presence of urgency associated with urine loss was defined as wet OAB. The degree to which quality of life was affected for each specific question in the ICIQ-OAB was based on a score that ranged from 0 to 10 (maximum of 40 points) and is referred to as ICIQ-OAB quality of life score. Higher scores indicate a greater severity of symptoms and, consequently, reflects greater impact of individual symptoms on patient's quality of life.

\section{Statistical analysis}

The SPSS software program, version 21.0 was used for the statistical analysis. The numerical variables representing age and scores were expressed as means and standard deviations or medians and interquartile ranges (IQR). The variables included in the analysis were: age, number of childbirth deliveries, schooling, urinary symptoms (urgency, urge incontinence, urinary frequency and nocturia), Roma IV criteria (straining during defecation, lumpy or hard stools, sensation of incomplete evacuation, sensation of anorectal blockage, manual maneuvers to facilitate defecation and $\leq 3$ defecations per week) and the women' score in the overactive bladder questionnaire (ICIQ-OAB).

The calculation of sample size took into consideration an assumption that $30 \%$ of constipated individuals would have a lower urinary tract disorder ${ }^{(7,8)}$. According to the hypothesis that $50 \%$ of these individuals would have a lower urinary tract disorder and 50\% would not, sample size was calculated at 291 women for a power of $80 \%$ and an alpha error of $5 \%$.

A univariate analysis using the chi-square test to compare proportions, with significance established as $P \leq 0.05$, was conducted to test the association between the presence of constipation in women and the following variables: age, number of deliveries, schooling and urinary symptoms. In addition, the association between Rome IV criteria and overactive bladder, dry overactive bladder and wet overactive bladder was made. The Mann-Whitney non-parametric test was performed to determine whether there was an association between the ICIQ-OAB quality of life scores and constipation.

For a more in-depth evaluation into the independent association between the presence of $\mathrm{OAB}$, dry/wet $\mathrm{OAB}$ in women and constipation, a univariate and multivariate analysis was conducted in which all independent variables (age, number of childbirth deliveries, schooling and constipation) with $P$-values $<0.10$ were inserted into the logistic model. The variables that were statistically significant at $P<0.05$ remained in the model during the multivariate analysis. The variables were inserted and removed manually. In the same way, to evaluate the independent association between the Rome IV criteria and $\mathrm{OAB} /$ dry $\mathrm{OAB}$, a multivariate analysis was conducted using binary logistic regression in which the independent variables (age, number of deliveries, schooling and Roma IV criteria) were included in the logistic model when p-values were $<0.10$, remaining in the model if they continued to be statistically significant at $P<0.05$.

\section{Informed consent}

Informed consent was obtained from all individual participants included in the study.

\section{Ethical approval}

All procedures performed in this study were in accordance with the ethical standards of the institutional and national research committees and with the 1964 Helsinki declaration and its later amendments.

\section{RESULTS}

A total of 516 women with a mean age of $35.8 \pm 6$ years and a mean of $2 \pm 1$ deliveries were evaluated. Constipation was found in $34.1 \%$ of the population studied. OAB was found in $15.3 \%$ of the women. Dry OAB (without incontinence) was found in $8.9 \%$ of the sample and wet OAB (with incontinence) in 6.4\%. TABLE 1 
TABLE 1. Characteristics of the study sample $(n=516)$ according to the presence of constipation.

\begin{tabular}{|c|c|c|c|c|c|c|c|}
\hline & & Non-con & ted & & Consti & & \\
\hline & $\mathrm{n}$ & $(\%)$ & $95 \% \mathrm{CI}$ & $\mathrm{n}$ & $(\%)$ & $95 \% \mathrm{CI}$ & $P$-value \\
\hline $\mathrm{OAB}$ & 39 & $(11.50)$ & $8.29-15.35$ & 40 & $(22.70)$ & $16.99-29.36$ & 0.00 \\
\hline Wet OAB & 17 & $(5.0)$ & $3.04-7.73$ & 16 & $(9.10)$ & $5.47-15.04$ & 0.07 \\
\hline Dry OAB & 22 & $(6.5)$ & $4.20-9.48$ & 24 & $(13.70)$ & $9.14-19.32$ & 0.01 \\
\hline $20-29$ & 52 & $(15.30)$ & $11.76-19.42$ & 29 & $(16.50)$ & $11.54-22.51$ & \\
\hline $30-39$ & 185 & $(54.40)$ & $49.9-59.66$ & 90 & $(51.10)$ & $43.76-58.47$ & \\
\hline $40-49$ & 73 & $(21.47)$ & $17.35-26.08$ & 47 & $(26.70)$ & $20.56-33.61$ & \\
\hline$>50$ & 30 & $(8.80)$ & $6.14-12.20$ & 10 & $(5.70)$ & $2.92-9.89$ & \\
\hline High school or more & 121 & $(35.80)$ & $30.63-40.79$ & 61 & $(35.30)$ & $27.90-41.92$ & \\
\hline Urinary symptoms (ICI & & & & & & & \\
\hline Frequent urination & 20 & $(5.90)$ & $3.73-8.78$ & 12 & $(6.80)$ & $3.75-11.30$ & 0.68 \\
\hline Nocturia & 66 & $(19.40)$ & $15.47-23.88$ & 54 & $(30.70)$ & $24.20-37.79$ & 0.00 \\
\hline Urgency & 39 & $(11.50)$ & $8.40-15.19$ & 40 & $(22.70)$ & $16.99-29.36$ & 0.00 \\
\hline Incontinence & 25 & $(7.40)$ & $4.92-10.51$ & 22 & $(12.60)$ & $8.21-18.02$ & 0.05 \\
\hline Total & 340 & $(65.89)$ & $61.82-69.89$ & 176 & $(34.11)$ & $30.11-38.28$ & \\
\hline
\end{tabular}

OAB: Overactive bladder; ICIQ-OAB: International Consultation on Incontinence Questionnaire - Overactive Bladder.

describes the characteristics of the sample according to whether or not women were constipated.

Overall, $22.7 \%$ of the constipated women were found to have OAB compared to a prevalence of $11.50 \%$ in the non-constipated group $(P=0.00)$ (TABLE 1$)$. Dry OAB was found in $13.7 \%$ of the constipated women compared to $6.5 \%$ of the non-constipated women $(P=0.01)$. No association was found between constipation and wet OAB (TABLE 1) and constipation was not found to be a predictive factor for the wet subtype in univariate and multivariate analyses (TABLE 2). Nevertheless, when ICIQ-OAB scores for quality of life were analyzed, median values were found to be higher in constipated women with wet $\mathrm{OAB}$, reflecting the poorer quality of life in this group (TABLE 3).

From urinary symptoms mentioned in the ICIQ-OAB questionnaire, urgency and nocturia were the most common and were significantly associated with FC (TABLE 1). The presence of urinary incontinence alone was found in a greater proportion among constipated women $(12.6 \%$ versus $7.4 \% ; P=0.05)$. On the other hand, as described above, when incontinence was associated with urgency (wet OAB), no association was found with FC. No

TABLE 2. Analysis of predictive factors for subtypes of overactive bladder.

\begin{tabular}{|c|c|c|c|c|}
\hline \multirow[b]{2}{*}{ Factors } & \multicolumn{2}{|c|}{ Dry OAB } & \multicolumn{2}{|c|}{ Wet OAB } \\
\hline & $\begin{array}{l}\text { Univariate } \\
(\boldsymbol{P} \text {-value })\end{array}$ & $\begin{array}{c}\text { Multivariate } \\
(P \text {-value }) \\
\text { OR }(95 \% \mathrm{CI})\end{array}$ & $\begin{array}{l}\text { Univariate } \\
(P \text {-value })\end{array}$ & $\begin{array}{c}\text { Multivariate } \\
(P \text {-value }) \\
\text { OR }(95 \% \mathrm{CI})\end{array}$ \\
\hline Age & 0.16 & 0.23 & 0.79 & 0.55 \\
\hline Number of childbirth deliveries & 0.54 & 0.59 & 0.88 & 0.96 \\
\hline Constipation & 0.01 & $\begin{array}{c}0.01 \\
2.47(1.27-4.81)\end{array}$ & 0.07 & 0.08 \\
\hline
\end{tabular}

OAB: overactive bladder. 
TABLE 3. ICIQ-OAB quality of life scores (ICIQ-QoL) for overactive bladder, dry overactive bladder and wet overactive bladder, according to the presence of constipation.

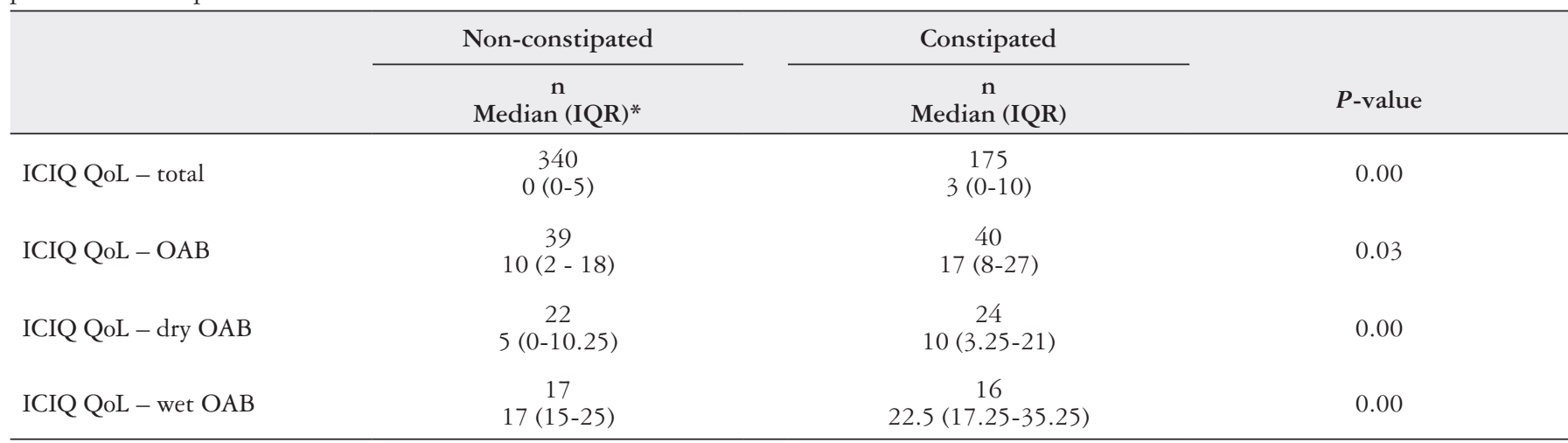

ICIQ-OAB: International Consultation on Incontinence Questionnaire - Overactive Bladder; IQR: interquartile range.

association was found between age or schooling and constipation (TABLE 1).

From Rome criteria, the presence of manual maneuvers to facilitate defecation was the bowel symptom for which a statistically significant association was found for both OAB subtypes (TABLE 4). In multivariate analysis, this criterion, together with presence of $<3$ defecations/week, were found to be independent predictors of OAB (TABLE 5). In multivariate analysis conducted to identify predictive factors of dry $\mathrm{OAB}$, the presence of $<3$ defecations/week was the only one of Rome criteria to remain in the final model (TABLE 6).

\section{DISCUSSION}

In the present study $\mathrm{FC}, \mathrm{OAB}$ and its subtypes wet and dry were identified in $34.1 \%, 15.3 \%, 6.4 \%$ and $8.9 \%$ respectively. In agreement with previous studies, FC was identified in $34 \%$ of women. Adibi et al., studying a young population (median age of 24 years, range 14-41 years) have shown a FC's prevalence of $32.9 \%{ }^{(9)}$. Howell et al. also described a FC's prevalence of $30.7 \% \%^{(10)}$. Like us, both studies have analyzed dates of a general base population based on Roma criteria. Prevalence rates in self-report measure and Roma Criteria seem to be equivalent, but Roma criteria allows more objective assessment of constipation ${ }^{(11)}$.

TABLE 4. Association between Rome criteria and overactive bladder, dry overactive bladder and wet overactive bladder.

\begin{tabular}{|c|c|c|c|c|c|c|c|c|c|}
\hline \multirow[t]{2}{*}{ Rome criteria } & \multicolumn{3}{|c|}{ Overactive bladder $\mathrm{n}(\%)$} & \multicolumn{3}{|c|}{ Dry overactive bladder n (\%) } & \multicolumn{3}{|c|}{ Wet overactive bladder n (\%) } \\
\hline & No & Yes & $P$-value & No & Yes & $P$-value & No & Yes & $P$-value \\
\hline Straining during defecation & $127(29.1)$ & $31(39.2)$ & 0.71 & $137(29.2)$ & $20(43.5)$ & 0.05 & $146(30.3)$ & $11(33.3)$ & 0.71 \\
\hline Sensation of incomplete evacuation & $108(24.7)$ & $23(29.1)$ & 0.41 & $117(24.9)$ & $13(28.3)$ & 0.62 & $120(24.9)$ & $10(30.3)$ & 0.49 \\
\hline Sensation of blockage & $48(11)$ & $15(19)$ & 0.05 & $55(11.7)$ & $7(15.2)$ & 0.49 & $54(11.2)$ & $8(24.2)$ & 0.03 \\
\hline Manual maneuvers & $37(8.5)$ & $17(21.5)$ & 0.00 & $44(9.4)$ & $9(19.6)$ & 0.03 & $45(9.3)$ & $8(24.2)$ & 0.01 \\
\hline
\end{tabular}

TABLE 5. Multivariate analysis of the Rome criteria - overactive bladder.

\begin{tabular}{lccc}
\hline & OD & $95 \%$ CI & $P$ \\
\hline Manual maneuvers & 2.214 & $1.125-4.357$ & 0.021 \\
$<3$ defecations/week & 2.178 & $1.230-3.855$ & 0.008 \\
\hline
\end{tabular}

Multivariate analysis, Rome criteria, overactive bladder.
TABLE6.Multivariateanalysisof the Romecriteria-dryoveractivebladder.

\begin{tabular}{cccc}
\hline OR & $95 \% \mathbf{C I}$ & $\boldsymbol{P}$ \\
\hline$<3$ defecations/week & 3.03 & $1.59-5.79$ & 0.001 \\
\hline
\end{tabular}

Multivariate analysis, Rome criteria, overactive bladder. 
No association was found with age. Although age was considered a risk factor for development of both FC and OAB, this finding is variable and reflects the multifactorial characteristic of these dysfunctions ${ }^{(1)}$. Likewise, neither FC nor OAB were found to be associated with schooling or with the number of childbirth deliveries in the sample population evaluated here.

FC was significantly associated with $\mathrm{OAB}$ in this sample. This finding is in line with others studies that reported the same association $^{(3,4,5)}$. Studies has been theorizing about the important role played by the more distal segments of the colon in the development of overactive bladder ${ }^{(4,5)}$. Findings from urodynamic studies have shown that rectal distension may alter bladder function and sensitivity in patients with lower urinary tract symptoms ${ }^{(12)}$. However, the association between constipation and lower urinary tract dysfunction does not appear to be the result only of local mechanical factors such as compression of the bladder by feces-filled bowel segment, consequently reducing bladder capacity, but predominantly of the existence of nerve connections between these organs that could result in cross-sensitization of pelvic structures. This connection would not be confined to upper lumbar and lumbosacral regions of the spinal cord, in which studies have detected the presence of convergent neurons from colon and bladder in the dorsal root ganglion that would receive afferent neural signals from these two organs ${ }^{(13)}$. This cross-talk would also involve convergent interneurons from lower bowel and bladder that exist in the spinal dorsal horn, as well as a population of neurons in pontine micturition center that would be synaptically linked to both aforementioned pelvic organs ${ }^{(14)}$. Studies using functional magnetic resonance imaging have reported alterations in the activation of certain regions of the brain such as the anterior cingulate gyrus and prefrontal cortex in both conditions ${ }^{(15,16)}$.

No association was found between wet $\mathrm{OAB}$ and FC. We believe that it occurred because our sample was mostly formed by young women. Contrary to the present finding, a study conducted with women over 40 years of age with $\mathrm{OAB}$ reported that latent $\mathrm{FC}$ (described as presence of two or more of Rome criteria) was the only factor associated with wet $\mathrm{OAB}$, with no association being found between $\mathrm{FC}$ and dry $\mathrm{OAB}^{(5)}$. The disparity in these results may be a consequence of a major difference in the populations studied, since the present study evaluated a random sample of relatively young women in the population (a mean age of $35.8 \pm 6$ years), while the other study analyzed women over 40 years of age attending a urology outpatient department. That feature may have led to a greater occurrence of $\mathrm{OAB}$ associated with urinary incontinence, a urinary disorder that is normally more common in older women. This finding suggests that the mechanism responsible for the appearance of $\mathrm{OAB}$ and its subtypes may vary according to age, with older women being more likely to develop structural changes in the pelvic floor such as pelvic organ prolapse, which would result in a greater association of $\mathrm{FC}$ and wet $\mathrm{OAB}$ in this age group. Therefore, our finding of association between manual maneuver and all OAB including wet subtype may suggest that this maneuver could represent a more longstanding stage of bowel dysfunction with impairment of pelvic floor. A future study with women under 40 years and above, also assessing the severity of constipation, may be useful in evaluating symptoms and signs most associated with OAB and its subtypes.

We found a poor Quality of life scores especially when wet $\mathrm{OAB}$ was associated with constipation. Men and women with urge urinary incontinence have worse quality of life scores ${ }^{(17)}$. OAB can lead to anxiety and depression by the urge to urinate and constant fear of leakage. In the same way, FC was associated with impaired on quality of life been comparable to that seen in other chronic conditions ${ }^{(18)}$. Our finding alerts to the negative effect of FC associated with $\mathrm{OAB}$ on quality of life of women affected by these disorders and regarding the need for appropriate management.

Manual maneuvers and $<3$ defecations/week were factors found to be predictive of $\mathrm{OAB}$, with these symptoms being found to increase the likelihood of this urinary dysfunction by a factor of two. This finding highlights the need for further investigation into urinary disorders in women with bowel symptoms to avoid the development of urinary complications resulting from late diagnosis. Moreover, in women with $\mathrm{OAB}$ but without urinary incontinence, referred to here as dry $\mathrm{OAB}$, the presence of $<3$ defecations/week was the only predictive factor for this dysfunction, increasing the likelihood of this urinary disorder by a factor of three. This emphasizes the risk involved in underestimating the importance of this bowel symptom when it is the only symptom present, and care should be taken not to overlook bowel dysfunction when fewer than two of the Rome criteria are present.

There are some limitations to the present study that need to be mentioned. The sample consisted predominantly of young women; therefore, the results cannot be extrapolated to older populations. Furthermore, since this was a population-based survey, which prevented $\mathrm{OAB}$ and FC from being evaluated in greater depth, causality cannot be inferred.

\section{CONCLUSION}

FC is associated with $\mathrm{OAB}$ and its dry subtype, particularly in younger population. In addition, this association is responsible for lower quality of life scores, especially when urinary incontinence is present. The presence of manual maneuvers and less than three defecations per week should direct us to look for OAB.

\section{ACKNOWLEDGEMENTS}

The authors are grateful to Júlia Cruz Santana and Rafaella Rabelo Macedo for their invaluable help in the data collection.

\section{Authors' contribution}

Abreu GE and Dourado ER contributed to data collection, data analysis, interpretation of the results and drafted the manuscript. Barroso Junior U contributed to the design of the study and critical revision. Alves DN, Araújo MQ and Mendonça NSP participated in data collection. All authors have read and approved the article for publication. 
Abreu GE, Dourado ER, Alves DN, Araujo MQ, Mendonça NSP, Barroso Junior U. Constipação funcional e bexiga hiperativa em mulheres: um estudo de base populacional. Arq Gastroenterol.

RESUMO - Contexto - A associação entre distúrbios urinários e constipação funcional vem sendo observada em crianças e adultos, sendo a constipação funcional uma queixa comum em indivíduos com bexiga hiperativa. Objetivo - Avaliar a prevalência de constipação funcional, bexiga hiperativa e seus subtipos seco/úmido em mulheres e determinar quais os sintomas intestinais estão mais associados e são preditores de bexiga hiperativa. Métodos Estudo de corte transversal com mulheres abordadas aleatoriamente em locais públicos. Os critérios de exclusão foram: anormalidades neurológicas/ anatômicas do intestino ou do trato urinário documentadas. A constipação foi definida como $\geq 2$ sintomas positivos daqueles listados nos critérios de Roma. Alterações urinárias (frequência urinária aumentada, urgência, incontinência e noctúria) foram definidas por um escore $\geq 2$ no respectivos itens do Questionário Internacional de Consulta sobre Incontinência - Bexiga Hiperativa. Foi denominada de bexiga hiperativa seca a presença de sintomas de urgência sem incontinência urinária e bexiga hiperativa úmida quando a urgência estava associada a incontinência urinária. Resultados - Foram entrevistadas 516 mulheres com idade média de 35,8 \pm 6 anos. As taxas de constipação funcional, bexiga hiperativa, bexiga hiperativa seca e bexiga hiperativa úmida na amostra estudada foram de 34,1\%,15,3\%,8,9\% e 6,4\%, respectivamente. Foi observada associação entre constipação funcional e bexiga hiperativa / bexiga hiperativa seca, sendo a constipação funcional fator preditor para esse subtipo de bexiga hiperativa $(\mathrm{OR}=2,47)$. $\mathrm{O}$ escore de qualidade de vida foi pior nas mulheres com constipação funcional em comparação com as não constipadas e ainda pior nas mulheres com constipação funcional associada a bexiga hiperativa úmida (mediana 22,5; IC 95\%: 17,25-35,25). A presença de manobras manuais estava significativamente associada aos dois subtipos de bexiga hiperativa. Os fatores preditivos independentes para bexiga hiperativa foram manobras manuais $(\mathrm{OR}=2,21)$ e $<3$ defecações/semana $(\mathrm{OR}=2,18)$, sendo este último o único fator preditivo para bexiga hiperativa seca $(\mathrm{OR}=3,0)$. Conclusão - Em mulheres, a constipação funcional está associada a bexiga hiperativa e seu subtipo seco, particularmente na população mais jovem. Além disso, essa associação é responsável por piores escores de qualidade de vida, principalmente quando a incontinência urinária está presente. A presença de manobras manuais e menos de três defecações por semana em mulheres devem nos direcionar a procurar por bexiga hiperativa.

DESCRITORES - Constipação intestinal. Bexiga urinária hiperativa. Mulheres. Sintomas do trato urinário inferior, complicações. Saúde do adulto.

\section{REFERENCES}

1. Mugie SM, Benninga MA, Di Lorenzo C. Epidemiology of constipation in children and adults: a systematic review. Best Pract Res Clin Gastroenterol. 2011;25:3-18.

2. Lacy BE, Mearin F, Chang L, Chey WD, Lembo AJ, Simren M, Spiller R. Bowel disorders. Gastroenterology. 2016;150:1393-1407.e5.

3. Sampaio C, Sousa AS, Fraga LG, Veiga ML, Bastos Netto JM, Barroso U Jr. Constipation and lower urinary tract dysfunction in children and adolescents: a population-based study. Front Pediatr. 2016:4:101.

4. Coyne KS, Cash B, Kopp Z, Gelhorn H, Milsom I, Berriman S, Vats V, Khullar $\mathrm{V}$. The prevalence of chronic constipation and faecal incontinence among men and women with symptoms of overactive bladder. BJU Int. 2011;107:254-61.

5. Maeda T, Tomita M, Nakazawa A, Sakai G, Funakoshi S, Komatsuda A, Ito Y, Nagata H, Tsukada N, Nakamura S. Female functional constipation is associated with overactive bladder symptoms and urinary incontinence. Biomed Res Int. 2017;2017:2138073.

6. Abrams P, Avery K, Gardener N, Donovan J; ICIQ Advisory Board. The International Consultation on Incontinence Modular Questionnaire: www.iciq.net. J Urol. 2006;175:1063-6.

7. Carter, D. \& Beer-Gabel. Lower urinary tract symptoms in chronically constipated women M. Int Urogynecol J. 2012;23:1785-89.

8. Cameron A, Fenner DE, DeLancey JO, Morgan DM. Self-report of difficult defecation is associated with overactive bladder symptoms. Neurourol Urodyn. 2010;29:1290-4

9. Behzad E, Pirzadeh S, Mohseni M. Bowel habit reference values and abnormalities in young Iranian healthy adults. Dig Dis Sci. 2007;52:1810-3.
10. Howell SC, Quine S, Talley NJ. Low social class is linked to upper gastrointestinal symptoms in an Australian sample of urban adults. Scand J Gastroenterol. 2006;41:65766.

11. Schmidt FM, Santos VL. Prevalence of constipation in the general adult population: an integrative review. Wound Ostomy Continence Nurs. 2014;41:70-6.

12. Panayi DC, Khullar V, Digesu GA, Spiteri M, Hendricken C, Fernando R. Recta distension: the effect on bladder function. Neurourol Urodyn. 2011;30:344-7.

13. McMahon SB, Morrison JF. Two group of spinal interneurones that respond to stimulation of the abdominal viscera of the cat. J Physiol. 1982;322:21-34.

14. Rouzade-Dominguez ML, Miselis R, Valentino RJ. Central representation of bladder and colon revealed by dual transsynaptic tracing in the rat: substrates for pelvic visceral coordination. Eur J Neurosci. 2003;18:3311-24.

15. Mugie SM, Koppen IJN, van den Berg MM, Groot PFC, Reneman L, de Ruiter MB, Benninga MA. Brain processing of rectal sensation in adolescents with functional defecation disorders and healthy controls. Neurogastroenterol Motil. 2018;30:e13228.

16. Ketai LH, Komesu YM, Dodd AB, Rogers RG, Ling JM, Mayer AR. Urgency urinary incontinence and the interoceptive network: a functional magnetic resonance imaging study. Am J Obstet Gynecol. 2016;215:449.e1-449.e17.

17. Coyne KS, Kvasz M, Ireland AM, Milsom I, Kopp ZS, Chapple CR. Urinary incontinence and its relationship to mental health and health-related quality of life in men and women in Sweden, the United Kingdom, and the United States. Eur Urol. 2012;61:88-95.

18. Belsey J, Geraint M (2010). Systematic review: impact of constipation on quality of life in adults and children. Aliment Pharmacol Ther. 2010;31:938-49. 